\title{
BMJ Open Help-seeking behaviours, opportunistic treatment and psychological implications of adolescent acne: cross- sectional studies in schools and hospital outpatient departments in the UK
}

\author{
Karishma Parimal Desai, ${ }^{1}$ Claire Martyn-Simmons, ${ }^{2}$ Russell Viner, ${ }^{3}$ Terry Segal ${ }^{4}$
}

To cite: Desai KP, MartynSimmons C, Viner R, et al. Help-seeking behaviours, opportunistic treatment and psychological implications of adolescent acne: crosssectional studies in schools and hospital outpatient departments in the UK. BMJ Open 2017;7:e016964. doi:10.1136/ bmjopen-2017-016964

- Prepublication history and additional material are available. To view these files, please visit the journal online (http://dx.doi. org/10.1136/bmjopen-2017016964).

Received 27 March 2017 Revised 18 June 2017 Accepted 20 June 2017

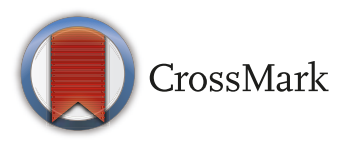

${ }^{1}$ Department of Medicine, University College London Medical School, London, UK ${ }^{2}$ Department of Paediatric Dermatology, University College London Hospitals NHS Foundation Trust, London, UK ${ }^{3}$ Department of General and Adolescent Paediatric Unit, UCL Institute of Child Health, London, UK

${ }^{4}$ Department of Adolescent Endocrinologist, University College London Hospitals NHS Foundation Trust, London, UK

Correspondence to Professor Russell Viner; r.viner@ucl.ac.uk

\section{ABSTRACT}

Background Acne vulgaris (acne) is a common adolescent skin condition. It is associated with negative psychological impacts and sufferers do not easily seek help, hence is undertreated.

Objectives We investigated the self-reported prevalence, severity and psychological sequelae of acne, together with assessing help-seeking behaviour and its barriers, in separate school and hospital samples. We explored opportunistic treatment by paediatricians.

Methods Self-reported survey with participants drawn from: (1) 120 adolescents aged 13-18 in a London tertiary paediatric outpatient department and (2) 482 adolescents from two London schools, aged 11-18. Adolescents confidentially and anonymously completed a questionnaire (paper or online) and those with acne completed the Cardiff Acne Disability Index (CADI) questionnaire.

Outcome measures To explore if acne is being addressed opportunistically in outpatient appointments and the behaviours associated with seeking help and psychological implications of acne.

Results Acne prevalence was reported as $58.3 \%$ in the clinic and $42.3 \%$ in schools, with $34.3 \%$ and $20.6 \%$ of participants having moderate acne (MA) or severe acne $(\mathrm{SA})$, respectively. The correlation between acne severity and CADI was significant (regression coefficient $=4.86$, $\mathrm{p}<0.005$ (MA) and 9.08, $\mathrm{p}<0.005$ (SA) in the hospital; 1.92, $p<0.001$ (MA) and 7.41, $p<0.005$ (SA) in schools). Severity of acne was associated with increased likelihood of seeing a doctor in both samples $(\mathrm{OR}=8.95$, 2.79-28.70 (MA) in the clinic and 1.31, 1.30-2.90 (MA) and 3.89, 0.66-22.98 (SA) in the community). Barriers to help seeking included embarrassment and believing doctors were unapproachable. Doctors addressed acne opportunistically in $2.9 \%$ of the sample, although $16.7 \%$ of those with MA and SA wished their doctor had raised it.

Conclusion Acne is common and has negative psychological implications, correlating with severity. Young people often forego seeking help and hospital clinicians rarely address acne opportunistically. Further work is needed to investigate how to reduce barriers to help seeking for acne.
Strengths and limitations of this study

Self-reported, age-appropriate validated questionnaires were used.

- There was a low response rate for the community study $(40.2 \%)$.

- Coeducational and state schools are not represented in this data set.

- A convenience sample strategy was used and therefore the results have limited generalisability.

\section{INTRODUCTION}

Acne is a chronic skin condition commonly affecting adolescents. ${ }^{12}$ Several studies report the incidence of acne in UK adolescents to range from $50 \%$ to $80 \% .{ }^{34}$ It is estimated that the worldwide prevalence of acne is around $9.4 \%$, making it the eighth most prevalent disease. $^{1}$

Acne can be particularly distressing for adolescents because it interferes with development of self-image and self-confidence, as assessed by emotional well-being questionnaires. ${ }^{35}$ Increasing severity of acne can lead to a greater degree of social impairment such as poor friendship and relationship formation. ${ }^{6}$ It is also associated with higher levels of frustration and depression ${ }^{7}$; however, the relationship between quality of life and severity of acne are poorly understood specifically for UK adolescents.

Despite the high psychological morbidities caused by acne, adolescents do not regard acne as a medical condition ${ }^{89}$ and in American studies, rates of help seeking were $<20 \%{ }^{10}$ Studies have concluded that embarrassment, stigma and misconceptions about acne, such as poor diet and hygiene are the likely causes that prevent young people from seeking help. ${ }^{11} 12$ There are also important racial differences in help-seeking 
behaviours, as highlighted in other studies. Black respondents were more likely to see a healthcare professional when compared with White respondents. Conversely, Hispanics had a lower likelihood of seeking help. ${ }^{10}$ Low adherence is a common problem, especially with acne as the results following treatment are slow. ${ }^{13}$ Twenty-four per cent of adolescents who use a topical treatment do not adhere to their treatment plan because of forgetfulness or the occurrence of side effects such as redness and dryness of skin. ${ }^{14}$

However, the proportion of UK adolescents who seek treatment for acne and from which medical specialty remains unknown. Past studies highlighted that difficulties in talking to the general practitioner (GP) and concerns over the confidentiality of the consultation were further barriers to help seeking. ${ }^{15}$ It is known that young people have health concerns that they would like help with but are not seeing their doctor for. ${ }^{16-18}$ Opportunistic addressing of acne by clinicians may be welcomed by young people and reduce this unmet health need. We are not aware of previous studies of help seeking and opportunistic treatment of acne in adolescents.

To address these knowledge gaps, we undertook a self-report survey in young people from a community setting (schools) and a clinical setting (hospital outpatients) to:

(1) Investigate the self-reported rate, severity and psychological sequelae of acne, among adolescents at general hospital clinic appointments (non-dermatological) and in the community. In addition, for those with acne, we assessed whether, and which type of medical advice has been sought;

(2) Investigate whether acne is being addressed in outpatient appointments and if not, whether the young person would like it to be.

Surveying adolescents in the clinic enabled assessment of whether doctors addressed acne opportunistically. The community study facilitated the assessment of severity and help-seeking behaviours for acne in the general population.

It is believed that there is a link between the two studies, as acne is common and individuals with acne in both samples may have psychological sequelae.

\section{METHODS}

\section{Study design and settings}

A cross-sectional study was conducted among adolescents using a self-reported questionnaire. Participants were recruited from two cohorts over February-March 2015. The first (community setting) recruited young people aged between 11 and 18 from two independent London schools, one independent all-boys school and one independent all-girls school. The second (clinical setting) was a dedicated adolescent outpatient department of a single large London teaching tertiary hospital, which treated patients aged 13-18 attending under a range of specialties, excluding dermatology.

\section{Participants}

\section{Community setting}

A convenience sample was recruited from pupils in years 7-13 (age 11 to 18 years) attending two UK independent schools. The schools were selected because of the wide catchment areas. Following agreement to participate by the head teacher, the patient information leaflet detailing the purpose of the study and the questionnaires were sent to all students via the school's intranet system. Of the 1200 eligible students in the two schools, $482(40.2 \%)$ returned the online questionnaire.

\section{Clinical setting}

Adolescent patients attending general outpatient clinics (with the exception of those attending dermatology clinics) over a 4-week period in January 2015 were asked to participate by $\mathrm{KD}$ and those interested were provided with a patient information leaflet and questionnaire pack. Those who wished to participate completed the questionnaire anonymously and confidentially while in clinic. Of the 200 adolescents approached in clinic, $80(40 \%)$ declined to participate, giving a final sample of 120, a response rate of $60 \%$. Note that the age range for the clinical service was 13-18 years, thus this was adopted for the clinical study.

\section{Data and instruments}

The self-report survey comprised three components. The survey could be completed by young people either online or on paper.

1. Acne Screening Questionnaire (see online supplementary appendix 1 and supplementary appendix 2). The questionnaire was designed for the purpose of this study and included questions on participants' perceptions of their own skin health, their degree of acne, use of healthcare and barriers to seeking treatment. Photographs were used of mild, moderate and severe acne as an aid.

2. Cardiff Acne Disability Index (CADI) Questionnaire (see online supplementary appendix 3). The CADI is a validated five-item questionnaire which assesses behavioural difficulties and emotional reactions to acne, self-confidence and perceived severity of acne. All items were summed to generate a total CADI score (out of 15). Scores 11-15 indicate severe impact, 6-10 moderate impact and $\leq 5$ mild impact. ${ }^{19}$

3. For the participants from the clinical setting, a question relating to opportunistic assessment or treatment of acne was asked.

\section{Outcomes}

The primary outcomes were opportunistic treatment of acne in outpatient appointments, as well as the behaviours associated with seeking help and psychological implications of it.

Secondary outcomes included investigating the self-reported prevalence and severity of acne among UK adolescents. 


\begin{tabular}{|c|c|c|}
\hline Clinical cohort & $\begin{array}{l}\mathrm{N}(\%) \text { of } \\
\text { respondents with } \\
\text { acne }\end{array}$ & $\begin{array}{l}\mathbf{N}(\%) \text { of } \\
\text { respondents } \\
\text { without acne }\end{array}$ \\
\hline $13-14$ & $16(22.9)$ & $17(34.0)$ \\
\hline $15-16$ & $31(44.2)$ & $18(36.0)$ \\
\hline $17-18$ & 23 (32.9) & $15(30.0)$ \\
\hline \multicolumn{3}{|c|}{ Community cohort } \\
\hline $11-13$ & $43(21.2)$ & $94(33.8)$ \\
\hline $14-16$ & $102(50)$ & $128(46.0)$ \\
\hline $17-18$ & 59 (28.9) & $56(20.1)$ \\
\hline
\end{tabular}

\section{Statistical analysis}

Analysis of closed questions involved descriptive statistics. Logistic regression was used to assess if there was a correlation between acne severity and help-seeking behaviours. Linear regression was used to test whether greater severities of acne correlated to a higher CADI score. Non-parametric tests (Mann-Whitney U Test and Kruskal-Wallis Test) were used to determine whether having a high CADI score influenced the decision to seek a doctor and if so, what medical specialty. Data were analysed using IBM SPSS Statistics V.22.

\section{Ethics}

The clinical study was granted ethical approval by Integrated Research Application System (NRES Committee South Central-Berkshire) (Reference=14/SC/1450) (see online supplementary appendix 4), and the community study was given approval by University College London (UCL) Research Ethics Committee (Project $\mathrm{ID}=6267 / 001)$ (see online supplementary appendix 5).

\section{RESULTS}

For age distribution and respondents for each cohort, see table 1 .

\section{Self-reported frequency and severity of acne (see tables 2 and 3)}

The peak acne prevalence was noted at 16 years (22 $(31.4 \%))$ in the clinical sample, and at age 15 (43 $(21.1 \%))$ in the community.

\section{Ethnicity}

Data on ethnicity were obtained for the clinical cohort alone. Out of those who had acne, 32 (45.7\%) were

$\begin{aligned} & \text { Table } 2 \\
& \text { determined for the clinic cohort }\end{aligned}$
\begin{tabular}{ll} 
Study population at recruitment & $n=200$ \\
Response to the questionnaire on the day & $n=120(60 \%)$ \\
Positive response for acne & $n=70(58.3 \%)$ \\
\hline
\end{tabular}

Table 3 Table showing how the analytical sample was determined for the community cohort

\begin{tabular}{ll}
\hline Study population at recruitment & $n=1200$ \\
Response to the questionnaire online & $n=482(40.2 \%)$ \\
Positive response for acne & $n=204(42.3 \%)$ \\
\hline
\end{tabular}

British White, 9 (12.9\%) were South Asian, 6 (8.6\%) were Black, $18(25.7 \%)$ were mixed race and $5(7.1 \%)$ did not specify.

\section{Previous medical management of acne}

Fifty-three $(75.7 \%)$ respondents in the clinic and 130 $(63.7 \%)$ respondents in the community reported that they had never sought help from health professional for management of acne.

In the clinic, participants with moderate severity of acne were more likely than those with mild to have seen a physician for management of acne $(\mathrm{OR}=8.95,95 \% \mathrm{CI}$ 2.79 to 28.70), after adjusting for age and gender. The OR for those with severe acne was not statistically significant $(\mathrm{OR}=0.99,95 \%$ CI 0$)$.

In the community cohort, adolescents with moderate and severe acne were more likely to have attained medical help for their skin, than those with mild acne $(\mathrm{OR}=1.31$, $95 \%$ CI 1.30 to 2.90 (MA) and $\mathrm{OR}=3.89,95 \%$ CI 1.66 to 22.98 (SA)), after adjusting for age and gender.

However, the type of health professional a respondent had seen or had accessed varied significantly. There was no statistically significant correlation between increasing severity of acne and the likelihood of seeing a dermatologist in either cohort $(\mathrm{p}<0.36$ in the clinic and $\mathrm{p}<0.19$ in the community).

There were a variety of reasons given for not having sought medical management of acne. For those with moderate and severe acne, the main reasons given were that they were too embarrassed or that their acne was not severe enough. Full results given below.

In the clinical cohort, those with mild acne, 28 (73.6\%) believed it was not severe enough, $6(15.8 \%)$ were too embarrassed, 0 believed their doctor was unapproachable, $2(5.3 \%)$ were too busy and $2(5.3 \%)$ did not give a reason. Out of those with moderate acne, $3(27.3 \%)$ believed it was not severe enough, $6(54.5 \%)$ were too embarrassed, 0 believed their doctor was unapproachable and $2(18.2 \%)$ were too busy. Out of those with severe acne, $1(25 \%)$ believed it was not severe enough and 3 $(75.0 \%)$ were too embarrassed.

In the community cohort, those with mild acne, 33 $(49.3 \%)$ believed it was not severe enough, $25(37.3 \%)$ were too embarrassed, $6(9.3 \%)$ believed their doctor was unapproachable and $3(4.5 \%)$ were too busy. Out of those with moderate acne, 7 (43.8\%) believed it was not severe enough, $7(43.8 \%)$ were too embarrassed, $2(12.4 \%)$ believed their doctor was unapproachable and 0 were too busy. Out of those with severe acne, $1(50 \%)$ believed it was not severe enough and $1(50 \%)$ was too embarrassed. 


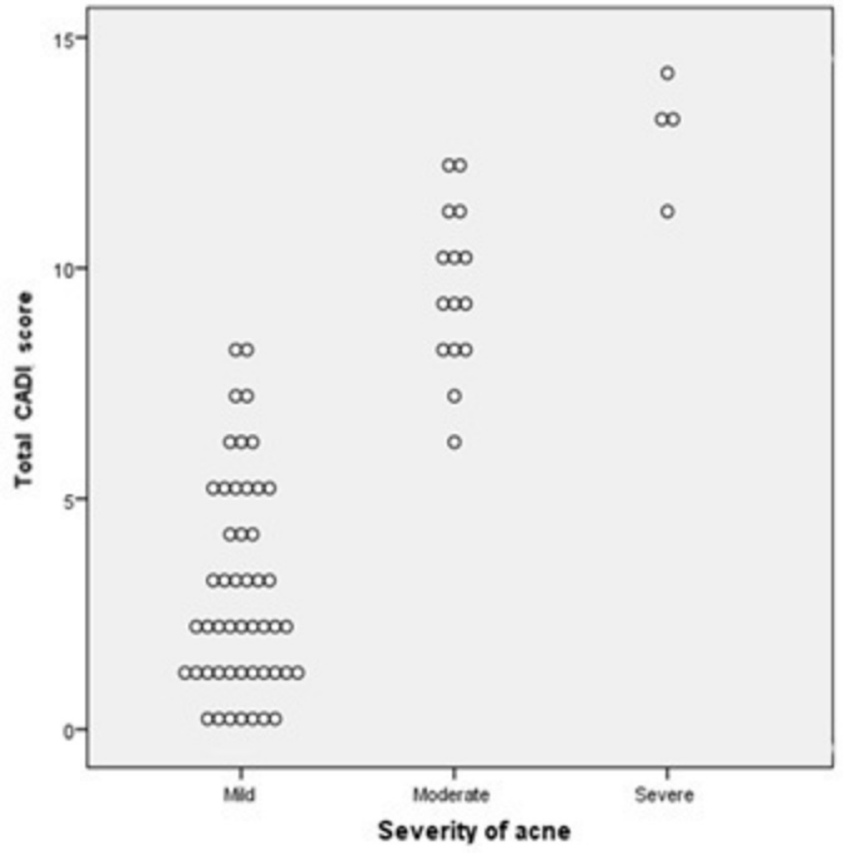

Figure 1 Distribution of CADI scores, according to severity, among the clinical cohort. CADI, Cardiff Acne Disability Index.

Community respondents reported that their doctor was unapproachable, but this was not reproduced in the clinical sample.

There were gender differences such that more males stated that their acne was not severe enough (23 (54.8\%) males compared with $14(51.9 \%)$ females in the clinical cohort and 23 (54.8\%) males compared with 20 (35.1\%) females in the community cohort). More females were embarrassed (9 (33.3\%) females compared with 7 (26.9\%) males in the clinical cohort and $28(49.1 \%)$ females compared with $14(33.3 \%)$ males in the community cohort).

\section{Psychological morbidity associated with acne}

The mean CADI score for the clinical cohort was 4.82 and for the community cohort, it was 4.84 (see figures 1 and 2). CADI scores were higher for females (achieving borderline significance in the clinical study; $\mathrm{p}=0.05$, and statistical significance, $\mathrm{p}<0.005$, in the community).

Linear regression analyses, adjusted for gender, showed that in the clinical cohort, an increase severity of acne, from mild to moderate and mild to severe, increases the CADI score by 4.81 and $9.08(\mathrm{p}<0.005)$, respectively. This is a statistically significantly result (see table 4 ).

In the community, adjusted analysis established that an increase severity of acne, from mild to moderate and mild to severe, increases the CADI score by $1.92(\mathrm{p}<0.001)$ and $7.41(\mathrm{p}<0.005)$, respectively. This is a statistically significant result (see table 5).

There were no significant differences in the median CADI score for those who had seen a doctor in the clinical sample (5) compared with those who had not (median 2; $\mathrm{p}=0.31$ ) or for the community sample (four for those who had seen a doctor; four for those who had not; $\mathrm{p}=0.89$ ).

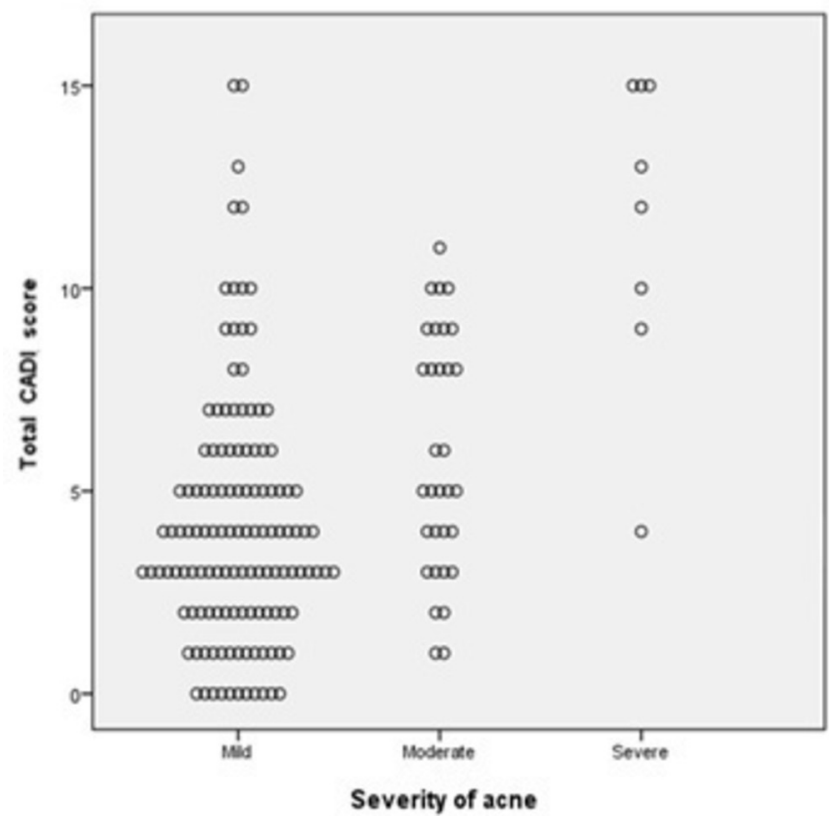

Figure 2 Distribution of CADI scores, according to severity, among the community cohort. CADI, Cardiff Acne Disability Index.

Total CADI scores for those who have seen GP, a paediatrician or a dermatologist were not significantly different, $\mathrm{p}=0.26$ in the clinic and $\mathrm{p}=0.24$ in the community.

\section{Opportunistic management of acne in outpatient clinics}

This was assessed only in the clinical study. Sixty-eight $(97.1 \%)$ adolescents with acne were not asked about their acne despite suffering from it.

Four $(16.7 \%)$ participants with moderate and severe acne wished that their doctor had asked them about their acne.

\section{DISCUSSION}

Our findings confirm in our highly selected cohorts, the rate of acne was similar to other UK-based studies. It affected $58.3 \%$ in the clinical cohort and $42.3 \%$ in the community cohort. Suffered from moderate and severe acne was $34.3 \%$ and $20.6 \%$, respectively. This is similar to other UK-based studies. ${ }^{20}$ There was consistent reporting of acne from each age category in the clinical cohort. In the community cohort, 102 (50\%)

Table 4 Association between moderate and severe acne and the Cardiff Acne Disability Index scores for clinical cohort

Regression coefficients, $95 \%$ Cls and $p$ values

\begin{tabular}{lll}
\hline $\begin{array}{l}\text { Explanatory } \\
\text { variables }\end{array}$ & Crude analysis & $\begin{array}{l}\text { Gender-adjusted } \\
\text { analysis }\end{array}$ \\
$\begin{array}{l}\text { Acne } \\
\text { (moderate) }\end{array}$ & $\begin{array}{l}5.40(4.03 \text { to } 6.77), \\
\mathrm{p}<0.005\end{array}$ & $\begin{array}{l}4.81(3.38 \text { to } 6.24), \\
\mathrm{p}<0.005\end{array}$ \\
$\begin{array}{ll}\text { Acne (severe) } \\
10.60(7.86 \text { to } 13.34),\end{array}$ & $\begin{array}{l}9.08(6.23 \text { to } 11.93), \\
\mathrm{p}<0.005\end{array}$ & $\mathrm{p}<0.005$ \\
\hline
\end{tabular}


Table 5 Association between moderate and severe acne and the Cardiff Acne Disability Index scores for community cohort

\begin{tabular}{lll}
\hline & $\begin{array}{l}\text { Regression coefficients, 95\% Cls and } \\
\text { p values }\end{array}$ \\
\hline $\begin{array}{l}\text { Explanatory } \\
\text { variables }\end{array}$ & Crude analysis & $\begin{array}{l}\text { Gender-adjusted } \\
\text { analysis }\end{array}$ \\
Acne (moderate) & $\begin{array}{l}1.70(1.50 \text { to } 2.89), \\
\mathrm{p}<0.006\end{array}$ & $\begin{array}{l}1.92(1.76 \text { to } 3.07), \\
\mathrm{p}<0.001\end{array}$ \\
Acne (severe) & $\begin{array}{l}7.45(5.24 \text { to } 9.65), \\
\mathrm{p}<0.005\end{array}$ & $\begin{array}{l}7.41(5.28 \text { to } 9.54), \\
\mathrm{p}<0.005\end{array}$ \\
\hline
\end{tabular}

14-16year olds responded, with a smaller representation of young people in the 11-13 (43 (21.2\%)) and 17-18 age groups $(59(28.9 \%))$. This may represent less acne in the younger and older age group and hence less motivation to respond; however, we do not have the data for non-responders. Our sample size precluded us assessing the influence of ethnicity on acne.

Ours is the first study to investigate the opportunistic treatment of acne among UK adolescents. Our study highlights the lack of proactive discussion about the young person's acne in the vast majority of paediatrician consultations (excluding dermatology consultations), with only $3 \%$ being asked about their acne despite almost a fifth expressing a desire for their acne to have been addressed by the doctor.

Our findings support previous reports that acne is associated with increased psychological morbidity that has a meaningful impact on the lives of the young people. Severity of acne was associated with worse psychological impact. Participants with acne scored higher scores on the CADI scale in both our samples, in both genders. It is important to note that these were self-reported scores. We did not however find a correlation between the CADI score and the likelihood of seeking help from a doctor.

We found that the majority of young people with severe acne do not seek help from a doctor. The main reasons given were embarrassment or that their acne was not severe enough. Other reasons were feeling their doctor was unapproachable or too busy. We identified gender differences in help seeking. In both samples, more males reported feeling that their acne was not severe enough to see a doctor, whereas a larger proportion of females felt embarrassed by their acne. This finding has been consistently reproduced by other studies with similar populations. ${ }^{21}$ Feeling that the doctor is unapproachable was a common reason among males and females in the community sample, but for none in the clinical sample. This could be because the clinical sample are healthcare users and know their doctors, whereas the community sample are less likely to be users and possibly believe doctors are unapproachable. Literature has also shown that anxiety specifically associated with acne can impact adolescents in seeking help in the first place; however, this was not present in our study. ${ }^{22}$

Studies have found that the most severe cases of acne are referred to a dermatologist ${ }^{23}$; however we did not find any significant associations between the severity of acne and the type of doctor seen. This may reflect issues relating to the power of the study and the small sample size, but could suggest that many with severe acne are not being referred to dermatology.

\section{Strengths and limitations}

The use of an age-appropriate, validated questionnaire used in this study is an important strength. Other disease-specific questionnaires assess the severity of the physical condition without exploring the psychological morbidities, whereas the CADI questionnaire allowed for the participants to record any negative psychological impacts. The validated scale allows for global comparisons. Our data are however subject to several limitations. Different methods of acne grading could affect comparisons of prevalence rates between studies. This study made use of an Acne Severity Grading Scale; however, another study that used the Leeds Revised Acne Grading System reported the prevalence to be in excess of $80 \% .^{9}$

One of the major limitations for the study is the non-response bias. Although a good sample size was obtained for the clinical study, there were $60 \%$ non-responders in community sample. It was not known whether the non-responders had similar rates of acne or not. One could speculate that those most severely affected by their skin were missed because they declined to participate. The study may have therefore underestimated the psychological impact of acne, making the result hard to generalise to the rest of the population. It was estimated that in the clinic, $40 \%$ of adolescents were not captured. Some adolescents did not complete the questionnaire due to time restraints. Follow-up of non-responders is not available for our dataset.

Varied literacy levels could account for non-response. Adolescents would have been unlikely to answer the questionnaire if they had difficulties understanding English. This was less concerning in the community sample because adolescents attending two top-ranking independent day schools in London would be expected to have a reasonable literacy level to answer the questionnaire. However, the tertiary hospital serves a wide, multiethnic population and this includes those who have a low educational attainment as well as those who are highly educated. It is possible that language and literacy barriers restricted those who answered the questionnaire to the latter group of people.

Two independent schools were used to collect this data, so results might not be generalisable to state-funded or grammar schools.

\section{Implications for practice}

In the clinical sample, adolescents were not asked by doctors about acne, despite their desire to have been asked. This could suggest doctors incorporating questions about whether the young person has any concerns about their skin as part of routine history taking. This is to ensure that doctors do not miss adolescents with acne who could benefit most from early intervention to prevent 
scarring and psychological sequelae. It is important that healthcare professionals are informed about how to manage acne of all severities. Help-seeking behaviours for adolescents with acne were low $(17(24.3 \%)$ in the clinical cohort and $74(36.3 \%)$ in the community cohort who had seen a doctor). These individuals may benefit from being referred for medical care, either by family, friends or by their GP. Doctors and teachers need to help young people recognise when they are suffering from acne. Educating adolescents that acne is common and treatable is vital. This could be done via low-cost interventions such as education programmes created by schools to encourage adolescents to seek help and how to go about doing so. Further options could use websites and social media or leaflets in schools and hospitals to inform young people about skin conditions, success of treatment and what to do if they suspect they are suffering from one. Doctors should be educated to and encouraged to consciously enquire about skin and mental health, regardless of gender. The treatment of acne should be guided by both acne severity and degree of quality of life impairment.

\section{CONCLUSIONS}

This study suggests a link between acne and significant negative psychological impact. Many adolescents do not seek help readily for acne. Closed questions on the questionnaire indicated that reasons for this include not thinking their acne is severe enough or embarrassment or they find their doctor unapproachable. Given that there are effective treatments that reduce the symptoms, it has illustrated the need for education of young people to encourage them to seek help for acne, encouraging GPs and paediatricians to facilitate discussions about treatment of the condition and ensure that healthcare professionals ask young people of both sexes about the impact that acne has on their mood and quality of life. This study used a small cohort; however, further studies using a multicentre approach could validate these findings. This can help shape the way doctors address and manage acne in hospitals and promote educational interventions in schools to encourage help-seeking behaviours. This could lead to improvements in seeking help and treatment of acne.

Acknowledgements Thank you to Mrs Wagner (Deputy Head and Head of Pastoral Care, South Hampstead School for Girls) and Mr McBroom (Deputy Head of Sixth Form, City of London School for Boys) for giving their consent to participate and all the staff at the tertiary hospital outpatient department. Thank you to all the patients and students who participated.

Contributors All four authors contributed to the write-up of the paper. KPD collected data, helped obtain ethical approval and conducted the analysis. CM-S helped refine the paper and gave her expert opinion as a dermatologist on the topics raised in this research. RV helped with the statistical analysis of the data and with obtaining ethics approvals. TYS supervised the research and helped formulate the patient information leaflets, questionnaires and data analysis. She also helped in obtaining ethics approval.

Competing interests None declared.

Patient consent Obtained.

Ethics approval IRAS and UCL REC.
Provenance and peer review Not commissioned; externally peer reviewed.

Data sharing statement Data are available on request to the authors.

Open Access This is an Open Access article distributed in accordance with the Creative Commons Attribution Non Commercial (CC BY-NC 4.0) license, which permits others to distribute, remix, adapt, build upon this work non-commercially, and license their derivative works on different terms, provided the original work is properly cited and the use is non-commercial. See: http://creativecommons.org/ licenses/by-nc/4.0/

(C) Article author(s) (or their employer(s) unless otherwise stated in the text of the article) 2017. All rights reserved. No commercial use is permitted unless otherwise expressly granted.

\section{REFERENCES}

1. Tan JK, Bhate K. A global perspective on the epidemiology of acne. Br J Dermatol 2015;172:3-12.

2. Bhate K, Williams HC. Epidemiology of acne vulgaris. Br J Dermatol 2013;168:474-85.

3. Smithard A, Glazebrook C, Williams HC. Acne prevalence, knowledge about acne and psychological morbidity in mid-adolescence: a community-based study. Br J Dermatol 2001;145:274-9.

4. Pawin $\mathrm{H}$, Chivot $\mathrm{M}$, Beylot $\mathrm{C}$, et al. Living with acne. A study of adolescents' personal experiences. Dermatology 2007;215:308-14.

5. Tasoula E, Gregoriou S, Chalikias J, et al. The impact of acne vulgaris on quality of life and psychic health in young adolescents in Greece. Results of a population survey. An Bras Dermatol 2012;87:862-9.

6. Halvorsen JA, Stern RS, Dalgard F, et al. Suicidal ideation, mental health problems, and social impairment are increased in adolescents with acne: a population-based study. J Invest Dermatol 2011;131:363-70.

7. Nijsten T, Rombouts S, Lambert J. Acne is prevalent but use of its treatments is infrequent among adolescents from the general population. J Eur Acad Dermatol Venereol 2007;21:163-8.

8. Gollnick HPM, Finlay AY, Shear N. Can we define acne as a chronic disease? Am J Clin Dermatol 2008;9:279-84.

9. Karciauskiene J, Valiukeviciene S, Stang A, et al. Beliefs, perceptions, and treatment modalities of acne among schoolchildren in Lithuania: a cross-sectional study. Int J Dermatol 2015;54:e70-e78.

10. Cheng CE, Irwin B, Mauriello D, et al. Self-reported acne severity, treatment, and belief patterns across multiple racial and ethnic groups in adolescent students. Pediatr Dermatol 2010;27:446-52.

11. Ritvo E, Del Rosso JQ, Stillman MA, et al. Psychosocial judgements and perceptions of adolescents with acne vulgaris: A blinded, controlled comparison of adult and peer evaluations. Biopsychosoc Med 2011;5:11.

12. DiTomasso R, Golden B, Morris H. Handbook of cognitive-behavioral approaches in primary care. New York: Springer Publishing Company, 2010.

13. Tidman MJ. Prompt treatment of acne improves quality of life. Practitioner 2012;256:15-17.

14. Snyder S, Crandell I, Davis SA, et al. Medical adherence to acne therapy: a systematic review. Am J Clin Dermatol 2014;15:87-94.

15. Anderson J, Lowen C. Connecting youth with health services. Canadian Family Physician 2010;56:778-84.

16. Jeannin A, Narring F, Tschumper A, et al. Self-reported health needs and use of primary health care services by adolescents enrolled in post-mandatory schools or vocational training programmes in Switzerland. Swiss Med Wkly 2005;135:11-18.

17. McPherson A. Adolescents in primary care. BMJ 2005;330:465-7.

18. Aarseth S, Dalen I, Haavet OR. Encouraging adolescents to contact their GP: a community-based trial. Br J Gen Pract 2014;64:e262-e267.

19. Motley RJ, Finlay AY. Practical use of a disability index in the routine management of acne. Clin Exp Dermatol 1992;17:1-3.

20. Mallon E, Newton JN, Klassen A, et al. The quality of life in acne: a comparison with general medical conditions using generic questionnaires. Br J Dermatol 1999;140:672-6.

21. Kellett SC, Gawkrodger DJ. The psychological and emotional impact of acne and the effect of treatment with isotretinoin. $\mathrm{Br} J$ Dermatol 1999;140:273-82.

22. Krowchuk DP, Stancin T, Keskinen R, et al. The psychosocial effects of acne on adolescents. Pediatr Dermatol 1991;8:332-8.

23. Corey KC, Cheng CE, Irwin B, et al. Self-reported help-seeking behaviors and treatment choices of adolescents regarding acne. Pediatr Dermatol 2013;30:36-41. 